\title{
¿Qué puede APORTAR la EDUCACIÓN CONTINUA a su carrera profesional?
}

Por : Dra. Dulce Ma. Guzmán Acevedo.

Farmacéutica

Coordinadora de Educación Continua.

ada día nuestras profesiones se ven enfrentadas a los nuevos conocimientos que modifican el abordaje y toma de decisiones de los problemas de salud que como profesionales especializados nos toca resolver.

De esta premisa es que nace la Educación Continua: para dar respuesta a la necesidad de fortalecer competencias técnicas y genéricas del profesional, que garanticen un mejor desempeño y una solidez en su formación, y así facilitar el acceso a nuevas oportunidades de trabajo o bien, para fortalecer la posición actual y quizás algo igualmente importante, mejorar el ingreso económico al mejorar la empleabilidad.

Complementando este supuesto agregamos que estas competencias genéricas constituyen un grupo de habilidades que son claves para que cada profesional obtenga mayores logros, entre ellos el desarrollo de la capacidad para aprender autónomamente, pues es precisamente la formación profesional continuada la única garantía contra la obsolescencia profesional.

Algunas de las habilidades que se fortalecen al participar en la educación continua son por ejemplo la capacidad de análisis, la capacidad de organización y planificación, la capacidad de crítica y autocrítica, la capacidad de aplicar conocimientos en la práctica y habilidad para adaptarse a nuevas situaciones. Cada vez que un profesional en ciencias de la salud toma un curso de educación continua está trabajando en la dirección de fortalecer esas competencias.
Por tanto mejora su perfil y capacidades técnicas para dar mejores respuestas a los problemas de salud que aborda.

Lo invitamos a hacer de la educación continua un quehacer que forme parte de su vida profesional. Visite el sitio de Educación Continua de nuestra Universidad donde puede encontrar toda nuestra oferta de cursos.

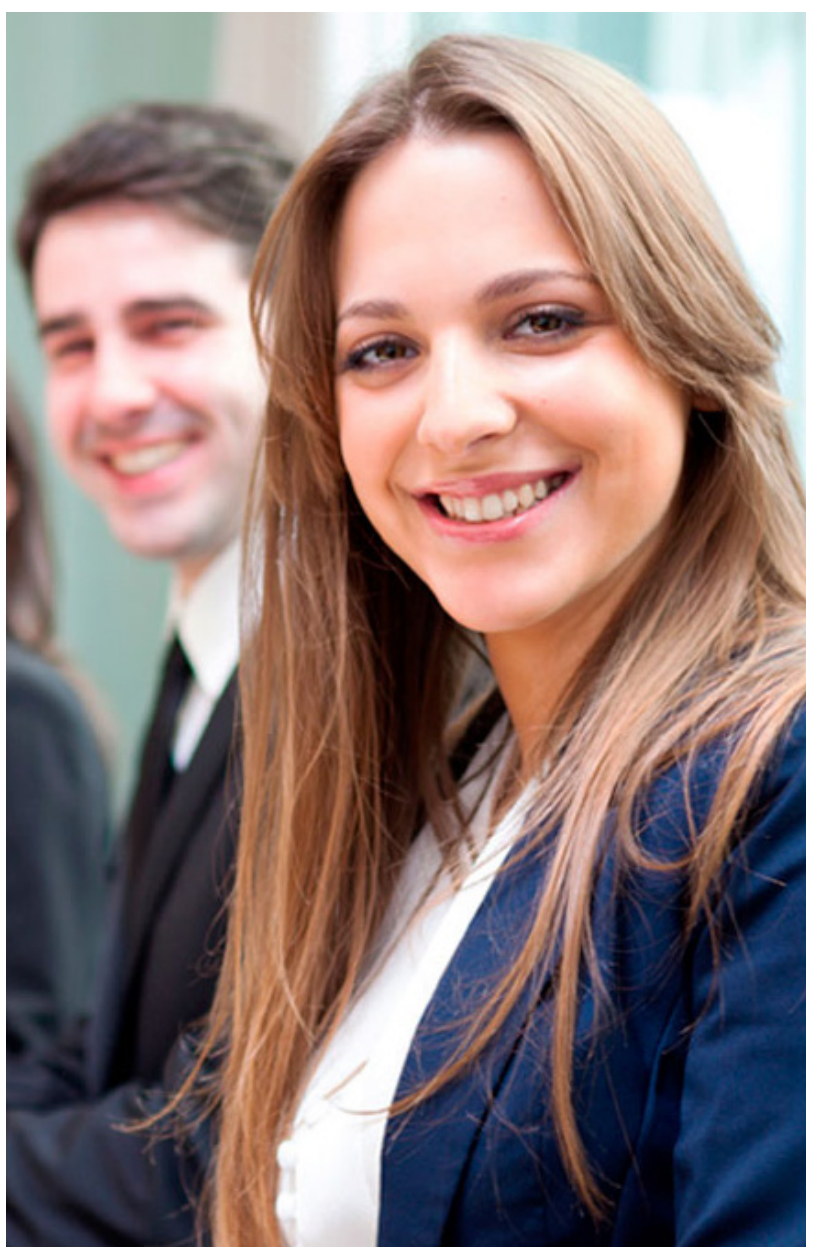

Referencias:

1. Educación Continua, Dra Dulce María Guzmán Universidad de Ciencias Médicas, San José 2017. 